\title{
PENERAPAN METODE PERMAINAN DALAM PENINGKATAN KETERAMPILAN MEMBACA PERMULAAN DI KELAS I SEKOLAH DASAR
}

\author{
Hayatinnupus $^{1}$ \\ Indah Permatasari ${ }^{2}$ \\ Program Studi Pendidikan Dasar \\ Universitas Pendidikan Indonesia \\ Email: nupus6969@gmail.com¹, ip.isosgi@gmail.com² \\ Artikel diterima: 9 Agustus 2018; disetujui: 31 Mei 2019
}

\begin{abstract}
The aims of the study are to (1) describe the steps for applying the word stacking method to improve the initial reading skills in grade I elementary school, and (2) improve the initial reading skills in first grade elementary school through the application of the game method. This research is a classroom action research conducted in two cycles. The technique of collecting data uses observation, interviews, and document analysis. Data analysis using thematic analysis, test the validity of the data using triangulation and reflexivity researchers. The average results of the first cycle of research are $97.89 \%$ while the second cycle is $98.28 \%$. The results of the study show that the application of the word play method can improve the initial reading skills in grade I elementary school.
\end{abstract}

Keywords: reading skill, initial reading, play method

\begin{abstract}
Abstrak: Tujuan dari penelitian untuk (1) mendeskripsikan langkah-langkah penerapan metode permainan susun kata untuk meningkatkan keterampilan membaca permulaan di kelas I sekolah dasar, dan (2) meningkatkan keterampilan membaca permulaan di kelas satu sekolah dasar melalui penerapan metode permainan. Penelitian ini merupakan penelitian tindakan kelas yang dilaksanakan dalam dua siklus. Teknik pengumpulan data menggunakan observasi, wawancara, dan analisis dokumen. Analisis data menggunakan analisis tematik, uji validitas data menggunakan triangulasi serta refleksivitas peneliti. Rata-rata hasil penelitian siklus I yaitu 97,89\% sedangkan siklus II yaitu $98,28 \%$. Hasil penelitian menunjukkan bahwa penerapan metode permainan kata dapat meningkatkan keterampilan membaca permulaan di kelas I sekolah dasar.
\end{abstract}

Kata kunci: keterampilan membaca, membaca permulaan, metode permainan

Pembelajaran membaca permulaan diberikan di kelas I dan II sekolah dasar. Tujuannya adalah agar kelak siswa memiliki kemampuan memahami, membaca kata-kata, dan kalimat sederhana dengan lancar dan tepat dengan lafal yang benar menurut tanda baca serta mampu menyuarakan dengan suara yang jelas sehingga teman lain dapat mendengarkan dengan seksama (Rahim, 2008). Dengan kata lain agar siswa mampu memahami isi bacaan, menyerap pikiran dan perasaan orang lain melalui tulisan.
Belajar membaca sangat penting bagi siswa, karena dengan bekal membaca adalah kunci keberhasilan di dalam menuntut ilmu dari awal sampai akhir. Membaca merupakan kebutuhan setiap insan, maka sebagai dasar siswa sudah dikenalkan dengan huruf, suku kata dan kalimat sehingga siswa dapat membaca dengan lancar.

Membaca permulaan merupakan membaca awal yang diberikan kepada siswa kelas rendah sebagai dasar untuk belajar lanjut (Suparno \& Yunus, 2008). 
Kemampuan membaca yang diperoleh di kelas I akan menjadi dasar pembelajaran membaca kelas-kelas berikutnya. Membaca permulaan bertujuan agar siswa dapat mengenal huruf, mengeja, membaca kata, dan kalimat sederhana dengan lancar dan tepat (Laeli, 2015). Ketika mengajarkan membaca permulaan, guru dapat menggunakan berbagai macam metode yang sesuai dengan karakteristik siswa. Untuk siswa yang belum mampu mengenal huruf, guru dapat menggunakan kartu huruf dan menggunakan metode abjad. Jika siswa belum mahir mengeja, maka guru dapat menggunakan kartu suku kata. Jika siswa sudah mahir mengeja maka guru dapat menggunakan kartu kata.

Penelitian ini berfokus untuk meningkatkan keterampilan membaca permulaan siswa kelas I sekolah dasar. Sebagai upaya meningkatkan keterampilan membaca maka dapat menggunakan metode pembelajaran inovatif. Metode pembelajaran adalah carayang digunakan guru dalam melaksanakan kegiatan pembelajaran agar terjadi proses belajar pada diri siswa sehingga tujuan pembelajaran tercapai (Ahmadi dan Amri, 2011; Sutikno, 2014). Metode pembelajaran yang digunakan peneliti untuk meningkatkan membaca permulaan yaitu metode permainan. Metode permainan adalah suatu cara penyajian materi pelajaran melalui berbagai macam bentuk aktivitas permainan untuk menciptakan suasana menyenangkan, serius tetapi santai sehingga siswa akan belajar dengan gembira (Saefudin, 2012; Sutikno, 2014).

Permainan yang digunakan dalam meningkatkan membaca permulaan pada siswa kelas satu sekolah dasar yaitu permainan susun kata. Permainan susun kata merupakan permainan menempel kata yang sesuai dengan gambar yang telah tersedia. Melalui permainan susun kata siswa akan belajar untuk mengeja dan memahami kata dengan bacaan (Nisak, 2013). Permainan ini dapat dilakukan secara individu atau kelompok. Dalam penelitian ini, permainan susun kata dilakukan secara individu karena untuk mengetahui minat baca siswa. Langkah-langkah permainan susun kata yaitu sebagai berikut: (1) guru menjelaskan tujuan dan proses permainan; (2) guru membagikan kertas berisi gambar yang akan ditempel kartu kata oleh siswa; (3) siswa menempel kata yang sesuai dengan gambar yang tersedia; (4) siswa bersama guru membahas hasil pekerjaan siswa; (5) siswa bersama guru menyimpulkan pembelajaran (Nisak, 2013).
Penelitian ini bertujuan untuk (1) mendeskripsikan langkah-langkah metode permainan dalam peningkatan keterampilan membaca permulaan di kelas I sekolah dasar dan (2) meningkatkan keterampilan membaca permulaan di kelas I sekolah dasar melalui penerapan metode permainan.

\section{METODE}

Metode penelitian yang digunakan adalah metode penelitian tindakan (action research) model Kemmis dan MC Taggart. Desain penelitian tindakan model Kemmis dan MC Taggart terdiri dari empat komponen yang meliputi perencanaan, pelaksanaan, pengamatan, dan refleksi (Arikunto, Suhardjono \& Supardi, 2011). Subjek dari penelitian ini yaitu siswa kelas I sekolah dasar yang berjumlah 38 siswa. Penelitian dilaksanakan di SDN 5 Nagrikaler, Purwakarta. Indikator kinerja penelitian yang diharapkan dalam ketuntasan hasil membaca permulaan siswa yaitu 90\% dengan KKM 70 .

Penelitian ini menggunakan tiga macam teknik pengumpulan data, yaitu observasi, wawancara, dan analisis dokumen. Observasi adalah teknik atau cara mengumpulkan data dengan jelas mengadakan pengamatan terhadap kegiatan yang sedang berlangsung (Madya, 2011). Kegiatan tersebut berkenaan dengan cara guru mengajar, siswa belajar dan lain sebagainya. Observasi dilakukan secara partisipatif, dimana peneliti ikut serta dalam kegiatan yang sedang berlangsung. Seperti halnya yang dinyatakan oleh Cohen, dkk (2008) bahwa untuk melihat perkembangan anak teknik yang paling baik untuk dilakukan adalah melalui pengamatan yang dapat menggambarkan perilaku, perkataan dan perasaan yang ditunjukan oleh anak.

Wawancara dilakukan oleh penulis untuk menggali informasi terkait dengan proses pelaksanaan kegiatan tersebut. Melalui wawancara ini diharapkan informasi terkait kelemahan dan hal-hal yang dirasa perlu diperbaiki berdasarkan pandangan guru dapat terakomodasi dengan maksimal. Sementara itu, analisis dokumen digunakan untuk melihat hasil keterampilan membaca siswa melalui kegiatan menyusun kata. Analisis data dalam penelitian ini menggunakan pendekatan kualitatif dengan teknik thematic analysis atau analisis tematik. Analisis tematik menurut Daly, Kellehear, \& Gliksman (dalam Fereday \& Cochrane, 2006) “... is a search for themes that merge as being important to the description of 
the phenomenon". Pernyataan tersebut memiliki arti bahwa analisis tematik merupakan suatu teknik yang digunakan dengan cara mencari tema-tema yang muncul dalam data penelitian dan merupakan bagian penting untuk mendeskripsikan fenomena yang terjadi.

Fereday \& Cochrane (2006) menambahkan bahwa pengidentifikasian tema dalam analisis ini dilalui dengan membaca dan terus membaca hasil temuan yang terjadi secara berulang sehingga membentuk suatu pola atau kategori yang akan dijadikan secara berulang sehingga membentuk suatu pola atau kategori yang akan dijadikan bahan untuk analisis. Sementara itu, Hancock \& Algozzine (2006) mengungkapkan bahwa analisis tematik adalah memberikan pelaporan dengan menekankan pada jawaban-jawaban atas pertanyaan penelitian, sehingga menghasilkan tema-tema pelaporan yang sesuai dengan pertanyaan penelitian. Adapun tahapan analisis data dalam penelitian ini yaitu melakukan pengodean data, kategorisasi kode ke dalam tema, dan menarik kesimpulan dari hasil koding (Thomas \& Harden, 2007; Alwasilah, 2010).

Validitas dan reliabilitas merujuk pada masalah kualitas data dan ketepatan metode yang digunakan untuk melaksanakan penelitian (Emzir, 2012). Adapun proses validitas dan reliabilitas pada penelitian ini dilakukan melalui dua cara yaitu triangulasi dan refleksivitas peneliti. Triangulasi adalah suatu proses penguatan terhadap bukti penelitian dengan cara menggunakan berbagai macam sumber, metode, peneliti, dan teori yang berbeda (Creswell, 2013). Creswell (2013) menyatakan bahwa pelaksanaan reflektivitas bertujuan agar hasil penelitian ini dapat dipertanggungjawabkan sehingga bersifat objektif dari interpretasi peneliti.

\section{HASIL}

Berdasarkan penelitian yang telah dilakukan, guru mampu melaksanakan pembelajaran sesuai skenario. Siswa tampak begitu antusias ketika guru mengenalkan permainan susun kata. Siswa cepat memahami penjelasan guru tentang prosedur permainan susun kata. Siswa melaksanakan permainan dengan tertib dan begitu bersemangat. Dalam penelitian ini pengukuran minat baca siswa dapat dilihat berdasarkan hasil belajar siswa melalui permainan susun kata serta hasil wawancara terbuka dan menyeluruh yang diberikan guru. Hasil permainan susun kata dapat dilihat melalui Tabel 1.

Hasil permainan susun kata di kelas I sekolah dasar pada siklus I pertemuan I yaitu 97,63\% sedangkan pada pertemuan II yaitu 98,15\%. Ratarata hasil permainan susun kata di siklus I yaitu 97,89\%. Hasil tersebut menunjukkan bahwa indikator kinerja penelitian yang diharapkan tercapai. Sementara itu, hasil permainan susun kata pada siklus II pertemuan I yaitu 98,15\% sedangkan pertemuan II yaitu $98,42 \%$. Rata-rata hasil permainan susun kata pada siklus II mencapai 98,28\%. Hasil ini juga menunjukkan ketercapaian indikator kinerja penelitian.

Selama penelitian berlangsung terdapat satu siswa yang belum mampu mengikuti permainan dikarenakan siswa tersebut masih kesulitan membedakan huruf. Guru memberi bimbingan penuh selama permainan susun kata berlangsung sehingga siswa tersebut mampu menyelesaikan permainan susun kata. Setelah siswa melaksanakan permainan susun kata, guru menanyakan perasaan siswa setelah bermain susun kata. Rata-rata siswa menjawab mereka senang dengan permainan susun kata karena mudah dikerjakan serta terdapat banyak gambar dan warna. Siswa juga menyetujui jika guru banyak memberi permainan pada pembelajaran karena siswa sangat senang bermain.

\section{PEMBAHASAN}

Aktivitas permainan sebagai pendukung kegiatan belajar anak masih kurang dipahami oleh orang tua dan masyarakat. Bermain dianggap sebagai kegiatan yang kurang bermanfaat dan membuangbuang waktu. Sedangkan pada kenyatannya, ada permainan yang sengaja dirancang oleh guru, orang tua atau perusahaan untuk mendukung pembelajaran anak. Hal ini dilakukan untuk memotivasi anak untuk belajar dengan menyenangkan, karena situasi yang diciptakan melalui permainan dapat membantu anak untuk menikmati proses belajar. Alat permainan juga dapat dikembangkan dari alam

Tabel 1. Hasil Permainan Susun Kata pada Siklus 1 dan 2

\begin{tabular}{ccccc}
\hline \multirow{2}{*}{ No } & \multirow{2}{*}{ Siklus } & I & II & \multirow{2}{*}{ Rata-rata } \\
\cline { 3 - 4 } & & $97,63 \%$ & $98,15 \%$ & $97,89 \%$ \\
2 & I & $98,15 \%$ & $98,42 \%$ & $98,28 \%$ \\
\hline
\end{tabular}


dan lingkungan sekitarnya yang dapat mendukung proses perkembangan anak.

Penelitian yang dilakukan Nuraini \& Isbadria (2018) menunjukkan bahwa setiap pembelajaran berbasis permainan di sekolah dasar memiliki langkah atau sintaks tertentu yang harus dilakukan saat belajar. Selain itu, dapat dilihat bahwa setiap permainan yang dilakukan memiliki efek positif pada kompetensi siswa, baik secara kognitif, afektif, dan psikomotorik. Beberapa pembelajaran berbasis permainan yang dibahas dalam penelitian ini menunjukkan bahwa permainan jelas memiliki efek positif terhadap perkembangan siswa sekolah dasar. Hal ini mendukung hasil penelitian yaitu rata-rata hasil permainan susun kata di siklus I dan siklus II yang menunjukkan persentase yang tinggi sesuai indikator ketercapaian.

Rata-rata siswa selama pelaksanaan penelitian memberi keterangan mereka senang dengan permainan susun kata karena mudah dikerjakan serta terdapat banyak gambar dan warna. Hasil penelitian ini sesuai dengan hasil penelitian yang dilakukan Fathan (2014) dan Eun \& Young (2014) yang menerapkan metode permainan dalam pembelajaran. Hasil penelitian Fathan (2014) menunjukkan bahwa pengajaran tata bahasa melalui permainan lebih baik daripada mengajar tata bahasa sebagai sistem formal (mengerjakan soal latihan pada buku). Penggunaan permainan tanpa mengesampingkan tujuan pembelajaran yang hendak dicapai. Kegiatan pembelajaran menjadi menyenangkan dan siswa tidak merasa bosan sehingga hasil belajar maksimal.

Sementara itu, hasil penelitian Eun \& Young (2014) menunjukkan bahwa permainan dapat dikembangkan sebagai metode penyampai pesan pembelajaran di tingkat sekolah dasar. Terdapat tiga tujuan dalam mengembangkan permainan, yaitu (1) memungkinkan siswa untuk memahami materi dengan lebih mudah, sistematis, dan menarik; (2) agar siswa termotivasi untuk belajar; (3) siswa dapat menggali banyak materi tanpa terbebani karena materi disajikan secara menyeluruh yang dikemas dalam bentuk permainan. Berdasarkan hasil penelitian yang telah dijelaskan dapat disimpulkan bahwa penerapan metode permainan susun kata dapat menumbuhkan minat baca di kelas I sekolah dasar.

\section{SIMPULAN DAN SARAN}

\section{Simpulan}

Berdasarkan penelitian yang telah dilaksanakan diperoleh kesimpulan bahwa langkah-langkah metode permainan susun kata sebagai berikut: (1) guru menjelaskan tujuan dan proses permainan; (2) guru membagikan kertas berisi gambar yang akan ditempel kartu kata oleh siswa; (3) siswa menempel kata yang sesuai dengan gambar yang tersedia; (4) siswa bersama guru membahas hasil pekerjaan siswa; (5) siswa bersama guru menyimpulkan pembelajaran. Rata-rata hasil permainan susun kata di siklus I yaitu 97,89\% sedangkan pada siklus II yaitu 98,28\%. Hasil ini menunjukkan ketercapaian indikator kinerja penelitian yaitu $90 \%$. Hasil ini juga menunjukkan bahwa penerapan metode permainan susun kata dapat menumbuhkan minat baca di kelas satu sekolah dasar.

\section{Saran}

Berdasarkan penelitian yang telah dilaksanakan, peneliti menyampaikan saran kepada pihak guru bahwa dalam menggunakan metode pembelajaran, guru tidak harus meniru langkah-langkah metode yang tercetak dalam buku. Guru berhak menciptakan metode pembelajaran sendiri yang sesuai dengan kemampuannya serta karakteristik siswa.

\section{DAFTAR PUSTAKA}

Alwasilah, C. (2010). Pokoknya Kualitatif. Jakarta: PT. Dunia Pustaka Jaya.

Arikunto, S., Suhardjono, Supardi. (2011).Penelitian Tindakan Kelas. Jakarta: Bumi Aksara.

Ahmadi, I. K. \& Amri, S. (2011). Paikem Gembrot. Jakarta: Prestasi Pustakaraya.

Cohen, D. H, dkk. (2008). Observing and Recording the Behavior of young Children, 5th ed. New York: Teachers College, Columbia University.

Creswell, J.W.(2013). Research Desain: Pendekatan Kualitatif, Kuantitatif dan Mixed. Yogyakarta : Pustaka Pelajar.

Emzir. (2012). Metode Penelitian Kualitatif: Analisis Data. Jakarta: Rajawali Press.

Eun, Y. P. \& Young, H. P. (2010). A Hierarchical Interface Design of a Puzzle Game for Elementary Education. International Journal of $u$ - and e-Service Science and Technology, 3(2), hlm.43-50.

Fathan, M. M. (2014). Using Games in Primary Schools for Effective Grammar Teaching: a Case Study from Sebha. International Journal of English Language \& Translation Studies, 2 (2), hlm.211-227. 
Fereday, J \& Cochrane, E.M. (2006). Demonstrating Rigor Using Thematic Analysis: A Hybrid Approach of Inductive and Deductive Coding and Theme Development. International Journal of Qualitative Methods, 5 (1), hlm 1-11.

Hancock, D.R \& Algozzine, B. (2006). Doing Case Study Research: A Practical Guide for Beginning Reseachers. London: Teachers College, Columbia University.

Laeli, D.N. (2015). Penggunaan Metode Permainan dengan Media Puzzle dalam Peningkatan Keterampilan Membaca Permulaan di Kelas I SDN 2 Tamanwinangun Tahun Ajaran 2014/2015. (Skripsi, 2015, UNS: tidak diterbitkan).

Madya, S. (2011). Penelitian Tindakan Action Research. Bandung: Alfabeta.

Nisak, R. (2013). Lebih dari 50 Games Kreatif untuk Aktivitas Belajar-Mengajar. Jogjakarta: Diva Press.
Nuraini, N. L. S., \& Isbadria, N. (2018, December). Implementation of Game-Based Learning in Elementary School: A Content-Analysis Study. In International Conference on Education and Technology (ICET 2018). Atlantis Press.

Rahim, F. (2008). Pengajaran Membaca di Sekolah Dasar. Jakarta: Bumi Aksara.

Saefudin, A. (2012). Penerapan Metode Permainan menggunakan Kartu Kosakata dalam Pembelajaran Bahasa Inggris Siswa Kelas V SD. (Skripsi, 2012, UNS: tidak diterbitkan).

Suparno \& Yunus, M. (2011). Keterampilan Dasar Menulis. Jakarta: Universitas Terbuka.

Sutikno, M. S. (2014). Metode \& Model-Model Pembelajaran. Mataram: Holistica.

Thomas, J \& Harden, A. (2007). Methods for the Thematic Synthesis of Qualitative Reseach in Systematic Reviews. London: Social science reseach unit. 